\title{
Comments on two subdermal implant articles
}

I enjoyed reading the two articles written by Sam Rowlands in the October 2010 issue of the Journal. ${ }^{12}$ They were comprehensive and gave valuable information to health care professionals providing a contraceptive subdermal implant service. There are, however, several points that require clarification and/or correction.

First, Norplant ${ }^{\circledR}$, the six-rod system, was manufactured by Leiras Oy, now Bayer Healthcare and distributed in the UK by Hoechst Marion Roussel, who felt that Norplant was no longer commercially viable following the launch of the single-rod implant, Implanon ${ }^{\circledR}$ in 1999.

Second, Norplant and Implanon had similar but not the same insertion site as stated in these articles. ${ }^{12}$ The 1993 data sheet for Norplant says that "the capsules should be inserted in the inner 
aspect of the upper non-dominant arm approximately $6-8 \mathrm{~cm}$ above the fold in the elbow". As there were six capsules they could not be placed in the groove between biceps and triceps as stated by Rowlands ${ }^{12}$ and normally sat subdermally over the biceps. Implanon's Summary of Product Characteristics (SPC) pre-2007 recommended that the arm should be "turned outwards and bent at the elbow. Implanon should be inserted at the inner side of the upper (non-dominant arm), about 6-8 cm above the elbow crease in the groove between the biceps and triceps".

Third, the resultant change in Implanon's SPC came from continuing discussions between the manufacturer and European, Australian and, most importantly, USA clinicians (as Implanon was about to be launched in North America). The change was not made solely "in response to repeated reports of nerve injury", ${ }^{2}$ as there had been very few (the neurovascular bundle is often covered by a thin layer of biceps/ triceps unlike diagrammatic representations $^{2}$ where it appears very 'exposed'). Experienced clinicians, particularly those in the USA, preferred the Norplant insertion site - the 'inner aspect' of the arm. Hence the current Implanon SPC reads that the woman should "lie on her back with her non-dominant arm (the arm which the woman does not use for writing) turned outwards and bent at the elbow. To minimise the risk of neural or vascular damage, Implanon should be inserted at the inner side of the non-dominant upper arm about $8-10 \mathrm{~cm}$ above the medial epicondyle of the humerus". This is not 'behind' the groove in the triceps ${ }^{2}$ but over the anterior aspect when the arm is in this position.

Fourth, I completely agree that "non-insertion is always due to human error" ${ }^{12}$ but the absence of an implant in women presenting following an 'implant insertion' is not always related to faulty 'inserter' technique. I have witnessed a patient pushing an implant down the insertion track and through the insertion incision immediately following a surgical abortion. I have also been involved in two other cases of 'non-insertion' where women had implants inserted, in the presence of their partners, by appropriately trained, experienced doctors. Both secretly wanted a baby and presented later in advanced pregnancy as 'non-insertions'. There are also a few reported cases in the literature of women $^{34}$ removing their own implants and I am sure readers of this Journal will be aware of others.

Self-removal provides an opportunity for financial gain through litigation and this should have been included in an article covering legal aspects of contraceptive implants. ${ }^{2}$ It is my experience that clinicians who have been appropriately trained and successfully insert a number of implants, continue this good practice. Occasional 'non-insertions' do not then occur. With the success of the UK training programme, the vast majority of true non-insertions and deep insertions are associated with a few inexperienced/ poorly trained practitioners not a faulty 'old' applicator.

I like Dr Rowlands' suggestion that all women should be asked to feel their implant before relying on it for contraception. If it cannot be easily felt then they should use condoms or abstain until help is sought. If clinicians, and unlike Rowlands, ${ }^{2}$ I include experienced local clinicians, cannot then clearly feel the implant, referral to the regional 'deep implant' centre is advised. Fatty tissue and muscle fibres can feel like a deeply placed implant. Multiple removal attempts result in scarred arms, unhappy women and occasionally neurological complications.

Very occasionally a decision is made not to attempt implant removal as the procedure may be too 'risky'." This may be a reasonable decision if future pregnancies are not desired. However etonogestrel implants continue to release hormone well beyond their 3 years. Assisted conception may result in successful ovulation in these women but the progestogen-induced atrophic endometrium may prevent implantation, even in the presence of exogenous hormone.

Finally, in our 2006 paper we reported that significant migration of the implant does not occur in the arm unless it is placed 'intramuscularly' not subcutaneously. ${ }^{5}$

\section{Diana Mansour, FRCOG, FFSRH}

Clinical Director, Sexual Health Services, NHS Newcastle and North Tyneside, Community Health, Newcastle upon Tyne, UK;

Diana.Mansour@newcastle-pct.nhs.uk

\section{Competing interests None.}

J Fam Plann Reprod Health Care 2011;37:119-120. doi:10.1136/jprhc.2011.0072

\section{REFERENCES}

1 Rowlands S, Sujan MA, Cooke M. A risk management approach to the design of contraceptive implants. J Fam Plann Reprod Health Care 2010:36:191-195.

2 Rowlands S. Legal aspects of contraceptive implants. J Fam Plann Reprod Health Care 2010;36:243-248.

3 Jaffer K, Whalen S. Self removal of Implanon: a case report. J Fam Plann Reprod Health Care 2005;31:248.

4 Gwinnell E. Expulsion of Implanon ${ }^{\circledR}$. J Fam Plann Reprod Health Care 2007;33:211.

5 Ismail H, Mansour D, Singh M. Migration of Implanon ${ }^{\circledR}$. J Fam Plann Reprod Health Care 2006;32:157-159 